\title{
Das naturwissenschaftliche Labor als Ort der "Verdichtung" von
Gesellschaft
}

\author{
Karin Knorr Cetina \\ Universität Bielefeld, Fakultät fiir Soziologie, Postfach 8640, D-4800 Bielefeld 1 \\ Unter Mitwirkung von: K. Amann, S. Hirschauer, K.-H. Schmidt
}

Zusammenfassung: Ziel der vorliegenden Arbeit ist es zl zeigen daB sich chs herschende "Feindbild" des Sozial en als dasjenige, das wissenschaftliche Resultate „verunreinigt" und von außen infiltriert, bei Betrachtung der Forschungspraxis der Naturwissenschaften nicht aufrecht ethalten läßt. Das naturwissenschaftliche Labor zeigt sich vi elmehr als ein Ort, an dem gesellschaftliche Praktiken fir epistemische Zwecke instrumentalisiert und in Apparaturen der Erkenntnisfabrikation transformiert werden: chs Labor is Ont der Bemächtigung und "Verdichtung" von Gesellschaft. Laboratorisienungsprozesse stellen die Bedingungen dafir her, daß Laboratorien als soziale Form funktionieren können. Sie werden als Prozesse des Übergangs al einer Erzeugungsogik beschrieben, die die Einbindung von Naturobjekten in kulturelle Interaktion - und dhit z B, die Beschleumigung von Erkenntnisprozessen - ermöglicht. Objekte und Indikatoren der Erzeugungsprozesse im Labor sind Zeichen, deren Sinn und Referenz etabliert werden muß. Soziale und altägliche Praktiken denen der Anbindung dieser Zeichen an Referenzobjekte ebenso wie der Etablierung von Vertrauen bzw. der "Sicherung" von Wahrheit. Zwei Praktiken werden vorgestellt die Verw endung des Dialogs als naturwissenschaftliches Vefahren (Gesprächsapparaturen) sowie der Einsatz des Körpers des Wissenschaftlers als Instrument und Garant von Wahrheit (körperliche Meßmethoden).

\section{Das „Feindbild" des Sozialen in der Wissenschaft}

Herkömmliche Vorstellungen vom „Wissenschaftlichen" beruhen, sofern hiermit wissenschaftliche Inhalte gemeint sind, auf einem „Feindbild" des Sozialen. Die neuere Wissenschaftssoziologie, van manchen auch genannt Sociology of Scientific Knowledge ${ }^{2}$, hat der bisherigen Wissenschaftssoztologie, Wissenschaftsgeschichte und Wissenschaftsphilosophie vorgeworfen, die Unterscheidung zwischen dem "Wissenschaftlichen" und dem

1 Der Ausdruck "Verdichtung" geht auf Wemer Rammert zurück, dem wir fir diese und andere Anregungen zu Dank verpflichtet sind Die hier veröffentlichten Ergebnisse wurden mit Unterstützung der Deutschen Forschungsgemeinschaft, der Friedrich Naumann Siftung und der Universität Bielefeld finanziert sowie mit Hilfe des Universitätsschwerpunkts -Wissenschaftsforschung an der Universität Bielefeld durchgeführt.

${ }^{2}$ Die neuere Wissenschaftssoziologie umfaßt zumindest die folgenden Ansätze: die "relativistischen" Ansätze der „Edinburgh School", die von einem Interessenmodell ausgeht, sowie von Harry Collins (z. B. 1975), den konstruktivistischen Laborstudienansatz, der hier vorgestellt wird (s. auch Latour und Woolgar 1979; Knar Cetina 1977, 1981 (1984)i Lynch 1985 und Traweek 1988), sowie den Diskursanarytischen Ansatz (Mulkay und Gilbert 1984). Für eine einführende Darstellung di eser Ansätze siehe Knorr Cetina und Mulkay (19B3).
"Sozialen" dazu zu benutzen, „bias", Betrug und Verzernungen in wissenschaftlichen Ergebnissen von objektiv wahren Inhalten zu trennen. Bei Ergebnissen, die als "falsch" diskreditiert wurden, wird nach sozialen Ursprüngen geșucht, während Inhalte, solange sie als wahr gelten, durch kognitive (wissenschaftliche, rationale) Faktoren erklärt werden (Bloor 1976: 141). Diese Vorgangsweise entspricht einem Modell der "Kontamination" des Wissenschaftlichen durch das Soziale: Es wird unterstellt, daß soziale Einflüsse wissenschaftliche Verfahren derart "kontaminieren", daß sie zu inkorrekten Ergebnissen führen. Die neuere Wissenschaftssoziologie kritisiert die Einseitigkeit dieser Vorgehensweise, bei der soziologische Erklärungen für wissenschaftliche Artefakte und Fehlschlüsse, aber nicht für als wahr geltende wissenschaftliche Leistungen geboten werden, und setzt dieser Asymmetrie eine "symmetrische" Vorgangsweise gegenüber. Sie richtet die Mannheimsche Frage nach der sozialen Konditionienung wissenschaftlichen Denkens ${ }^{3}$ insbesondere an das als „wahr" und "korrekt" geltende naturwissenschaftliche Wissen.

${ }^{3}$ Diese Frage wird von Mannheim in seiner Schrift "Ideology and Utopia". (1954) gestellt. Die neuere Wissenschaftssozid ogie richtet diese Frage - in erweiterter Fassung - erstmalig in ihrer Geschichte an de Naturwissenschaften 
In der neueren Wissenschaftssoziologie hat das Interessenmodell (Bames 1977; Barnes und MacKenzie 1979) anf die Mannheim'sehe Problemstellung die direkteste Antwort gegeben. Nach diesem Modell sind bei der Artikulation und Durchsetzung (natur)wissenschaftlicher Resultate und Theorien wissenschaftsinterne und wissenschaftsexteme kognitive und soziale Interessen beteiligt, wobei Klasseninteressen durchaus eingeschlossen sind. So stelt etwa MacKenzie (1981) einen dirckten Zusammenhang zwischen der theoretischen Kontroverse, die Pearson und Yule um die Entwickhung statistischer Koeffizienter (z. B. Pearson's,$\left.r^{\prime}\right)$ geführt haben und den entsprechenden gesellschaftspolitischen Interessen bzw. Klassenlagen der Beteiligten fest. Die Kontamination des Wissenschaftlichen durch das Soziale wird hier durch ein Modell der Interessenverflechtung ${ }^{4}$ und Widerspiegelung ersetzt. Das Soziale infiltriert un- ter geeigneten Bedingungen selbst in seiner krudesten Form (z B. Klasseninteressen) $)^{5}$ wissenschaftliche Ergebmisse, wie awa statistische Formeln, und spiegett sich in den ihnen zugrunde liegenden Annahmen wider. Mit dem Modell der Interessenverfechtung wird die Negativvorstellung vom Sozialen aufrecht erhalten. Das Soziale penetriert, läßt sich nicht abhalten von, kompromittiert die Entstchung und Aufrechterhaltung selbst der „reinsten" (mathematischen) wissenschaftlichen Ideen. Das Soziale ist kein Positivum bei der Wissensgewinning auch wern es sich auf ,wahre" Ergebnisse ebenso wie auf falsche anwenden läßt. Die Kritk an diesem Interessenmodell zielt entsprechend darauf $a b$, das Wissenschaftliche wieder vam Sozialen $z$ befreien ( $\mathrm{z}$ B. Galison 1987). ${ }^{6}$

Die im folgenden präsentierten Ergebnisse entstarmen dem konstruktivistischen Ansatz in der neueren Wissenschaftssoziologie. Dieser unter-

\footnotetext{
4 Barnes (1977) und Bames und Mackenzie (1979) sprechen van wissenschaftsexternen (Klassen)Inter essen, die wissenschaftsinteme, kognitive Interessen stützen und afrecht erhalten.

5 "Krude" aus der Sicht einer Wissenschaftsforschung, de von der Abschottung des Wissenschaftlichen von externen Einflußnahmen, insbesondere in Form von Interessen scaialer Gruppienungen oder politischer Macht, ausgeht.

${ }^{6}$ Galison's Kritik bezicht sich auf eine andere Arbeit im Rahmen des Interessensmodells, zeigt aber die fir solche Kritiken charakteristische Argumentation.
}

scheidet sich vom Interessenansatz $u$. a dadurch, daß keine Präjudizien darüber eingeführt werden, wie das Wissenschaftliche im Sozialen verankert erscheint. Der Konstruktivismus etabliert die soziale Konstruiertheit wissenschaftlicher Tatsachen durch das Forschungshandeln und die Überzeugungspraktiken der Teilnehmer als empirisch fundiertes Ergebnis. Sein wesentlichstes Kennzeichen ist, daß er das, was wir als "wahr" und ,wirklich" bezeichnen, als Konsequenz statt als Ursache der Erzeugnisse der technischen Kultur der modernen Naturwissenschaft betrachtet. Im Unterschied zur ,relativistischen" Richtung in der neueren Wissenschaftssoziologie (z.B. Collins 1981) leugnet der Konstruktivismus nicht die Relevanz von "Naturphänomenen" in der Wissenschaft. ${ }^{7} \mathrm{Er}$ versucht vielmehr zu zeigen, wie diese „Phänomene" als „unabhängige" und „natürliche", d.h. als zu einer anderen als der Sozialordnung gehörige, im Wissenschaftsbetrieb konstituiert werden. Der Kanstruktivismus beschreibt den Konstruktionscopparot, aus dem Realität, ,wie sie wirklich ist", hervorgeht. Er setzt wissenschaftliche Produkte in Relation zu ihre m Erzeugungsproze $\beta$ in der technischen Kultur der Wissenschaft und nicht in Relation zur "Natur". Fur den Konstruktivismus ist es daher wichtig, diese technische Kultur an Ort der Realisierung der entsprechenden Erzeugungsprozesse zu untersuchen, Da dieser Ort in den meisten Fallen das (natur)wissenschaftliche Labor ist, gewinnt das Labor Bedeutung als notwendige Einheit der Untersuchung der technischen Kultur. Für die Untersuchung wird hierbei die in situAufzeich nung der Praktiken der Teilnehmer durch ,Entdeckungs"-Verfahren ${ }^{8}$ gefordert, die die Distanz zur Realisienungsform dieser technischen Kultur minimieren. Dieser Forderung liegt die Erfahrung zugrunde, daß zur Untersuchung der Konstruktivi-

\footnotetext{
${ }^{3}$ Collins ${ }^{1}$ relativistische Studien (z.B. 1975) konzentrieren sich typischerweise auf „Negativbeweise": etwa auf die Frage, wanum de natürliche Welt bei der Konstruktion wissenschaftlicher Erkenntnis nur "eine kleine oder nicht-existente Rolle" spielen kann (1981: 3). Die Leugnung der Relevanz von "Naturphänomenen" konstituiert, wie man sagen könnte, das relativistische Forschungsprogramm.

${ }^{8}$ Hierbei erscheinen audio-visuelle sowie ethnographische Beobachtungsverfahren am vielversprechendsten, wăhrend Befragungsverfahren wegen des vorausgesetzten Vor-Wissens sowie wegen ihrer Distanz ar Realităt, auf de sie Berig nehmen, kaum geeignet erscheinen.
} 
tat der Naturwissenschaften eine Untersuchung der infinitesimalen Details der Erzeugungspraktiken im Prozeß ihrer Durchführung notwendig ist,

Ziel der vorliegenden Arbeit ist es zu zeigen, daß sich das reine Feindbild des Sozialen als dasjenige, das Wissenschaftlichkeit kontaminiert oder infiltriert, bei Beobachtung der konstruktiven Praxis der (Natur)wissenschaften nicht aufrecht erhalten läßt. Das Labor erscheint vielmehr als ein Ort, on dem gesellschaftiche Praktiken fir epistemische Zwecke instrumentalisiert und in Erzeugungsverfahren von Wissen transformiert werden Das Labor ist, um es anders auszudrücken, ein Ort der ",Verdichtung" - und nicht etwa ein Ort der ,Verdïnmung" und epistemischen Irrelevanz - von $\mathrm{Ge}$ sellschaft? Die Wissenschaften haben offenbar seit langem die Tatsache ihrer Einbettung in eine soziale Welt zu ihren Zwecken genutzt. Die Wissenschaften werden vom "Sozialen" nicht nur beeinträchtigt (kontaminiert oder infiltriert), sondern sie „bemächtigten" sich sozialer Praktiken als Instrumente der Erkenntnisfabrikation. Diese „Bemöchtigung" ist unserer Auffassung nach an Laboratorisierungsprozesse gebunden - sie verstärkt sich mit dem Übergang von einer Wissenschaft zur Laborwissenschaft. Soziale und alltaggliche Praktiken, wie z.B. Formen der Interaktion, sind notwendige Glieder in den Verarbeitungsketten des wissenschaftlichen Labors; sie erscheinen in die instrumentelle hardware des Labors nahtlos eingegliedert. Das Labor ist in diesem Sirn die soziale Form der Wissenschaft.

Aber was ist ein Labor? Im folgenden wird zunächst der Prozeß der Laboratorisierung als Übergang al einer Erzeugungslogik charakterisiert und am Beispiel einiger Laborformen illustriert. $\mathrm{Ab}$ schnitt 3 stellt Laboratorien als Einrichtungen dar, die (,objekt-lose") Zeichen prozessieren. Abschnitt 4 und 5 geben Beispiele furr soziale und alltägliche Praktiken an, die sich in den untersuchten Laboratorien zum technischen Instrument verdichtet finden: sie illustrieren die Verwendung des Dialogs als Verfahren sowie den Einsatz des Körpers des Wissenschaftlers als Instrument.

\footnotetext{
9 Im "verdünnten" und epistemisch irrelevanten Sinn werden die Wissenschaften wohl allgemein als Teil der sozialen Welt gesehen - etwa insofern, als Wissenschaftlersoziale Wesen darstellen. Die Diskussionen in der Wissenschaftsforschung ebenso wie das "Feindbild" des Sozialen be2iehen sich auf die Frage der epistemischen Relevanz sozialer Variablen.
}

\section{Das Labor als Erzeugungsprozeß}

\subsection{Laboratorisierung als Übergang zu einer Erzeugungslogik}

Nach konstruktivistischer Auffassung ist die Laboratorisierung einer Wissenschaft gekennzeichnet durch den Ubergang zu einer Erzeugungslogik, die, wie in Abschnitt 3 gezeigt wird, ,irreale Gegenstănde" etabliert. Die Betrachtung von Laboratorien als Orte, die durch ihre Erzeugungslogik gekennzeichnet sind, ist intuitiv plausibel, wem man die in verschiedenen Laboratorien ablaufenden Handlungsprogramme empirisch beobachtet: Diese scheinen nämlich weniger darauf ausgerichtet, Wirklichkeit zu beschreiben als Wirklichkeit zu erzeugen (und dann zu beschreiben). So ist z. B. in der Teilchenphysik Ziel des Baus der enormen Beschleuniger und Detektoren die Generierung und Messung von subatomaren Teilchen, die unter natürlichen Bedingungen nicht oder nicht meßbar vorhanden sind. Die Resultate der Teilchenphysik können nur deshalb gewonnen werden, weil diese sich nicht auf die Beschreibung (Messurig) von Wirklichkeit beschränkt, sondern die zu messende Wirklichkeit generiert. Die ständige Anpassung des Labors in der Teilchenphysik an die Erfordernisse immer kleinerer, zunehmend ephemerer Teilchen durch immer größere und taurere Maschinen ist von dieser Logik der Erzeugingsno"wendigkeit getragen.

Laboratorien stellen lokale Handlungskontexte dar, die in eingegrenzter Weise auf bestimmte Erzeugungsvorgănge spezialisiert sind Die Erzeugbarkeit des gesuchten Produkts - und nicht etwa dessen. Übereinstimmung mit irgendeiner unabhängigen „Natur" - validiert hierbei das Behandlungsprogramm des Labors sowie die "Wrklichkeit" des Produkts. Laboratorien sind lokale Handlungskontexte, die in Hinblick aff Untersuchungsobjekte "Nischen" etablieren, Sie stellen domestizierte, "artifizdelle" Handlungskontexte dar, hinsichtlich derer ,Natur" zur Umwelt des Labors wird. Untersuchungsobjekte werden, sofern sie aus einer "natürlichen" oder ,alltäglichen" Umwelt stammen, im Labor mit einer neuen ,Lebenswelt" konfrontiert, innerhalb derer sie als $\mathrm{Ob}$ jekte neu konstituiert werden. Kennzeichen von Laboratorien ist es, daß urspringliche Untersuchungsobjekte in ihnen unsichtbar werden; sie werden zu Impulsen, Reaktionskomponenten u. ä. "denaturiert". Man kann das Ausmaß der Laboratorisierung einer Wissenschatt am Ausmaß messen, in dem die Untersuchungsobjekte aus ihrer 
ursprünglichen Existenzform gelöst und im Labor als Objekte neu konstituiert werden.

Man nehme als Beispiel eine Entwicklung, die sich gegenwärtig in der Astronomie abzeichnet. Die Astronomie ist, wie man meinen könnte, eine klassische „Feld'Vissenschaft; es gelingt ihr nicht, ihre planetaren und interstellaren Untersuchungsobjekte aus ihrer ursprünglichen Umwelt zu lösen. Oder etwa doch? Die Astronomie hat sich in der Tat lange Zeit anf die Beobachtung des Nachthimmels - seit Galilei mit dem Teleskop - beschrānkt. Seit mehr als hundert Jahren bedient sie sich allerdings zusätzlich eines Aufzeichmungsinstruments, der photographischen Platte, mit Hilfe derer sie Photonen einfängt und prozessiert. Die Astronomie wurde damit von einer Wissenschat, die $\mathrm{Na}$ turphänomene „überwacht", zu einer Wissenschaft, die Bildaufzeichnungen dieser Phänomene verarbeitet. Seit 1976 tritt eine weitere Entwicklung in den Vordergrund, die auf eine Ablösung der photographischen Platte durch CCD chips hinausläuft. 'U Das Licht des Halleyschen Kometen wurde im Jahre 1982 von einem gigantischen 200 Zoll Spiegel des Haie Teleskops am Berg Palornar gesammelt und anf charge-coupled devices (CCDs) fokussiert. CCD chips stellen grundlegende Veränderungen einer ,imaging technology" dar. Sie ermöglichen durch ihre einfache Digitalisierbarkeit vor allem auch den Einsatz von Computertechnologien zur Auswertung und Übertragung astronomischer Daten. Werden sie, wie das seit mehr als einer Dekade die Astronomen beschäftigt, in Verbindung mit Weltraumteleskopen verwendet, so verbessert die Astronomie hierdurch nicht nur die Qualität ihrer Daten, sie wird von der Beobachtung ihres "Feldes" durch Astronomen auch vollständig unabhängig.

Was wird durch den Übergang von einer „Feld"wissenschaft, der Astronomie der Überwachung des Nachthimmels, zu einer "Labor"wissenschaft, der Astronomie als bildverarbeitender Wissenschaft, bewirkt? Offensichtlich erscheinen zurmindest die folgenden drei Prozesse:

1. Untersuchungsobjekte werden durch ihre Loslösung aus der "natürlichen" Umwelt, d. h, durch ihre Verbildlichung und Digitalisierung, im Handlungskontext des Labors kontinuierlich präsent gehalten.

${ }^{10}$ Für eine zusammenfassende Beschreibung dieser Entwicklung siehe Smith und Tatarewicz (1985).
2. Die interessierenden Prozesse erscheinen durch den Übergang al einer Zeichen(Bild)technologie "miniaturisiert".

3. Der Gesamtprozeß wird beschleunigt. Anstelle der Gebundenheit an planetare und stellare Zeitabläufe sowie an bestimmte Beobachtungslokalitäten in der südlichen Hemisphäre treten kontinuierliche Auswertungsprozesse weltweit verstreuter Astronomen, die an die elektronische Übertragung der gewonnenen Daten angeschlossen sind.

Die genannten Prozesse "entkoppeln" Untersuchungsobjekte aus ihren "natürlichen" Organisationsbedingungen und "rekonstitui eren" sie innerhalb derer kultureller Akt eure. Untersuchungsobjekte werden im Labor ,in Relation" zu diesen Akteuren gesetzt. Sie werden durch ihre Verkleinerung (oder Vergroß $B$ erung ${ }^{11}$ ) in Hinblick auf kulturelle Akteure, durch ihre Anpassung an deren Lokalität und Temporalität, in kulturelle Interaktion eingebunden. Die Interaktion mit ihnen wird durch solche Formen der "Relationierung" erst kontinui erlich ermöglicht. Laboratorisi erungsprozesse stellen die Bedingungen dafür her, daß Laboratorien als soziale Form funktionieren können. Die Einbindung in und Neukonstitution von Un. tersuchungsobjekten in der Interaktionsumwelt des Labors ist im übrigen mit einer Steigerung von Artikul ationsmöglichkeiten verbunden. Interaktionsumwelten sind zeitlich strukturierte, beschl euntgungsfähige Umwelten, die durch die Abfolge der Artikulationsveränderungen der Teilnehmer spezifiziert werden. Im vorliegenden Fall haben wir es gegenüber einer nicht "laboratorisierten" Wissenschaft mit einer Steigerung der Definitionsmacht des Forschers gegenuber dem Untersuchungsobjekt zu tun, bei der Faktoren wie stăndige Zugänglichkeit der Objekte, schnellere $\mathrm{Ab}$ wicklung und Wiederholbarkeit, Kontrollmöglichkeiten u. ă. gegenüber der Ausgangssituation eine Rolle spielen. Aber auch Untersuchungsobjekte erhalten innerhalb des Behandlungsprogramms des Labors Definitionsmacht; das Labor hat, wie man sagen könnte, den Zweck, diesen Objekten spezifische, auf die Interaktionsumwelt bezogene

11 Die subatomaren Objekte der Teilchenphysik kämen z.B. nur curch entsprechende Vergrößerungen van Maschinen (callida) in genügender Menge erzeugt und damit fiir kulturelle Akteure handhabbar gemacht werden. Die Spuren subatomarer Partikel milssen transformiert und in Darstellungen (,Event displays") entsprechend vergrößert werden. 
Artikulationen $\mathrm{zu}$ entlocken. Die Definitionsmacht der Untersuchungsobjekte zeigt sich $u$. $a$. in den Veränderungen des Behandlungsprogramms des Labors.

Für den Erfolg dieser Hervorlockungsarbeit erscheint es wesentlich, daß sie auf lokalen Artikulationssteigerungen basiert: Die konstituierten $\mathrm{Ob}$ jekte finden sich nur im Labor, nicht in der, äußeren" Umwelt, und sie können nur im Labor hergestellt werden. Der Übergang in die „Normalwelt" eines im Labor artikulierten Objektes ist daher problematisch, worauf etwa durch Anpassung der "Normalwelt" an die Laborverhältnisse, oder durch ,Normalisienung" der erzeugten Objekte reagiert werden kann. Diese und andere Aspekte der Erzeugungslogik von Laboratorien realisieren sich in verschiedenen Wissenschaftsbereichen verschieden. Laboratorien haben in verschiedenen Bereichen unterschiedliche instrumenteHe Formen. Hiezu einige Beispiele aus den von uns gegenwätig untersuchten Disziplinen der Molekularbiologie, Teilchenphysik, Künstlichen Intelligenz und Sexualforschung ${ }^{12}$

\subsection{InstrumenteUe Formen von Laboratorien: einige Beispiele}

Das vielleicht am ehesten konventionellen Vorstellungen naturwissenschaftlicher Forschung entsprechende Labor ist das "Arbeitsbanklabor" der M6lekularbiologie. Das Labor ist ein Raum, der Utensilien und Geräte zur Durchführung von Wachstums-, Entwicklungs- und Behandlungsprozessen beherbergt, die die Wissenschaftler zu „Experimenten" kombinieren. Es ist sozusagen eine „Behausung" für spezielle Bedingungen und Gegenstände, mit deren Hilfe Experimente komponiert werden können. Die Vorstellung vom Labor als Nische, als einer ausgegrenzten und erzaugten Umwelt, ist hier in räumlicher Form realisiert Charakteristisches Mobilar in diesen Labors ist die Arbeitsbank, an der die Teilnehmer hantieren.

${ }^{12}$ Diese Bereiche werden in vier laufenden, mehrjahrigen Laborstudien (Untersuchungen wissenschaftlicher Forschungslaboratorien durch direkte Beobactitung) am Institut fir molekulare Zellbiologie in Göttingen, am CERN in Genf (Trilchenphysik), am Philips Forschungsiaboratorium Hamburg (Künstliche Intelligenz/Informatik) sowie an der Abteilung fir Sexualforschung der Universitätskliniken Hamburg-Eppendorf untersucht Die Studien basieren aff ethnographischen Beobachtungen und Audioaufnahmen durch einen in die jeweiligen Institute/Abteilungen plazierten Ethnographen.
Das Labor der Molekularbiologie weist, wie andere natuwissenschaftliche Laborformen, Gruppenstrukturen auf. Diese sind Korrelat der ständigen Präsenz aller fưr alle in der răumlichen Einheit des Labors sowie der damit in Verbindung stehenden Gesprächskultur (s. Abschnitt 4). Betrachtet man den Leiter der Einheit, so ist diese Präsenz allerdings eingeschränkt. Die Verbindung arr Unwelt wird im Labor der Molekularbiologie offenbar durch die teilweise Externalisierung des Leiters realisiert. Der Leiter gehört nicht zum Labor, sondem zu administrativen Apparaten bzw. zur Wissenschaftlergemeinde. $\mathrm{Er} / \mathrm{Sie}$ ist hierbei nicht nur Bindeglied zur "scientific Cammunity", sondem Teil derselben und vertritt diese im Labor. Indikatoren dieser Außenzugehörigkeit der Leiter sind z. B. das Ausmaß ihrer Abwesenheit von der Einheit sowie die Art der Anwesenheit und Tätigkeit im Labor (oft keine ,hands on" Forschungstätigkeit, Verwendung eines Großteils der Zeit auf Außenkontakte, z. B. Telefonate, Sitzungen, Konferenzen u. ä.). In den von uns untersuchten Einheiten ist der Leiter u a. Importeur einer Außen$z e i t, \mathrm{~d}$. h. einer von den Fortschritten und Vorhaben der Konkurrenz bestimmten ,Konkurrenzzeit", die fir die Arbeit der Einheit bestimmend ist.

Eine solche teilweise bis vollständige Externalisierung des Leiters kennzeichnet auch das Labor der Teilchenphysik, das sich ansonsten drastisch vom Arbeitsbanklabor unterscheidet. Zwar weist auch dieses Labor Gruppenstrukturen auf, doch kommen diese nicht durch die ständige Präsenz aller für alle in der gemeinsamen ,Behausung" des Labors zustande, sondem erscheinen an Kollaboration gebunden - Gruppen werden durch gemeinsame Arbeit am gleichen Modul eines Experimentes etabliert. Das wesentlichste Kennzeichen des Labors der von uns untersuchten Teilchenphysik (Experiment UA2 am CERN) - wie übrigens auch anderer Bereiche der Physik ${ }^{13}$ - liegt wohl darin, daß das Labor im Innem einer mehrteiligen ,Megamaschine" gesucht werden muß. Diese umfaßt typischerweise eine Apparatur, die Teilchen (z.B. Protonen und Anti-Protonen) aus ihrer ,natürlichen" Einbettung (z.B. Wasserstoffatomen) löst und zur Reaktion ,anregt" (z.B. durch Beschleunigung der Teilchen); aus Apparaturen (Detekto-

13 Kleinere Vergleichsstudien $z$ den oben genamnten Laborstudien wurden und werden in der Atomplysik sowie in der Laserphysik im universitären Bereich durchgefithrt. 
ren), die die Spuren der erzeugten Reaktionen (die Spuren neuer Teilchen) wahrnehmen bzw. registrieren sowie aus solchen, die die erzangten Signale prozessieren und darstellen (elektronische Verarbeitung durch Eventbuilder-, Display- und Analyse-Programme).

Die verschiedenen Apparaturen sind untereinander $\mathrm{zu}$ integrierten Systemen verbunden: die Erzeugung. Messung und Beschreibung der interessierenden Teilchen erfolgt in integrierter Weise im Innem der Megaapparatur. Apparaturen sind also nicht nur lokal eingesetzte, instrumenteile Hilfsmittel für die Aktivitäten von Wissenschaftlem, die selbst die Integration zwischen Verfahrensschritten und -Geräten herstellen. Die Apparaturen der Physiker sind Originalexperimente, nicht Werkzeuge, ein Großteil der Arbeit experimenteller Physiker wird auf den Entwurf, den Aufbau, das Testen, den Umbau und Wiederaufbau der entsprechenden Mega-Apparaturen verwendet. Was um die Apparatur herum in den experimentellen Räumlichkeiten (und oft auf den Schreibtischen) der Physiker zu sehen ist, dient meist direkt dem Bau, Umball oder der Rep aratur der Apparatur. Der umgebende, auch "Labor" genannte Komplex ist Serviceeinrichtung für die Maschine, die das eigentliche Labor darstellt. In der von uns ebenfalls beobachteten Atomphysik werden die Geräte als „Kisten" oder "Dosen" bezeichnet d.h. als Behälter, die man öffnen und schließen kann, und bei denen es darauf ankommt, was sich im Inneren befindet. ${ }^{u}$

Eine weitere Laborform, die wir im Bereich der Kinstlichen Intelligenz und Informatik vorfinden (vgl. Schmidt 1988), könnte man als „Ringlabor" bezeichnen Zentralstüpk dieser Laborform sind mehrere, miteinander verbundene Rechner, die man sich als einen Ring vorstellen kann, an den einzelne Wissenschaftler (Mathematiker, Informatiker, Physiker $u$. a.) angeschlossen erscheinen.

Diese Laborform ähnelt auf den ersten Blick dem Labor der Physiker: Ihr Kernstück sind Maschinen (Rechner). Allerdings werden diese weder von den Teilnehmem konstruiert noch handelt es sich um Originale, deren Lebensdauer und Lebenszyklus mit denen eines Experiments identisch sind. Die Maschinen stellen vielmehr athnlich den Gerăten in der Molekularbiologie Werkzeuge dar, die verschiedensten Klienten und Zwecken zur Verfü-

H Siehe dazu im Detail den Forschungsbericht von Dembowski und Krause (1987) gung stehen. Die Teilnehmer, die sie verwenden, sind Nutzer, nicht Operateure oder Konstnukteure. Die einzelnen Bestandteile des Netzes van Maschinen, in die sich die Teilnehmer einloggen können (Mainframe Rechner, Lisp-Maschinen, Array-Prozessoren, Display-Geräte, Drucker) escheinen zwar verbunden, addieren sich jedoch nicht zu einer Megaapparatur auf, wie in der Fyy. sik. Die Verbindung zwischen den Maschinen hat vielmehr die Funktion, den Zugang zu allen in Frage kommenden Geräten, zu allen Beabeitungsstationen und $\mathrm{zu}$ allen Teilnehmem (iber „mail"- und ,phone"utilities) zu ermöglichen. Die Laborform erscheint somit weniger durch die Ma schinen selbst, als durch den Zugang, den das Netz eröffnet, definiert.

Die Verbindung zum Netz und zu den Netzteihehmem wird über Terminals hergestellt. Solche Anschluß-Stellen sind im untersuchten Forsctungsbereich in großer Zahl und an verschiedensten Otten vorhanden; der Zugang ist, wie man sagen könrte, (örtlich) beliebig, er wird von jedem Ort aus leidt gemacht. Die Tătigkeit der Teilnehmer erscheint im Prinzip räumlich ungebunden in einem Alsmaß, wie das von keiner der anderen untersuchtten Wissenschaften behauptet werden kann. Sie is nicht zuletzt aus diesem Grund in höherem Ausmaß individuelle Arbeit als die Tätigkeit der Molekularbiologen und Physiker: die Tätigkeit von Wis senschaftlem am Terminal, die an einen Ring von Maschinen angeschlossen sind, erweckt, so è Teilnehmer, die Vorstellung von ,Pferdeboxen": jeder Wissenschaftler operiert fir sich alleine in einer „Box", die zum Maschinenring über das Terminal geöffnet, von anderen Terminals oder Teilnehmern aber abgeschottet ist.

Die vierte, gegenwärtig untersuchte Laborform, das Labor der Sexualwissenschaft im Bereich der Untersuchung von Transsexualität, ähnelt dem Ringlabor der künstlichen Intelligenz insofern, ats es keine Gruppenstruktur, wohl aber eine Verbundstruktur anfweist (vgl. Hirschauer 1987). Allerdings wird diese nicht maschinell ermöglicht, sondem durch Zirkulation des Untersuchungsobjektes (,Transsexuelle") sowie schriftlicher Materialien zustande gebracht. Im vorliegenden Fall

\footnotetext{
15 Der Laborbegriff wurde in den ersten Laborstudien (Latour und Woolgar 1979; Knorr Cetina 1981 (1984); Lynch (1985) auf Laboratorien in den experimentellen Naturwissenschaften eingeschränkt. Diese Begriffsverwendung wird mit der durchgeführten Studie im Bereich der Sexualforschung aufgehoben.
} 
stellt das Labor einen Verbund verschiedener medizinischer Disziplinen sowie nicht-medizinischer Professionen dar. Die psychotherapeutisch ausgerichtete Sexualforschung steht hierbei als diejenige Disziplin, die das Vorliegen von Transsexualität bestimmt und die Weiterleitung der Untersuchungsobjekte vornimmt, im Zentrum des Labors. An sie werden Untersuchungsobjekte von Hausärzten, Gynäkologen oder auch Selbsthilfegruppen überwiesen und von ihr werden sie weitergeleitet an die Endokrinologie (zur Hormonspiegelüberprüfung und Hormontherapie), an Hautärzte und Kosmetik (zur Veränderung der Körperoberfläche, z.B. Enthaarung), an die Chinurgie (ar Durchführung von "Geschlechtsurnwandlungs"Operationen), sowie an das Amtsgericht (zwecks Namensănderung und gerichtlicher Bestätigung des Geschlechtswechsets.

Die im Labor erstellte Tatsache ist das vom Transsexuellen gesuchte, andere Geschlecht. Die gesteigerte Definitionsmacht des Labors ergibt sich aus dem MscAencharakter dieses Verbundes, in dem Personen mit bestimmten Symptomen diese als "Transsexualităt" deklarieren und sich als "Transsexuelle" einer Behandlung unterzichen können. Transsexuelle tauchen als solche systematisch erst im Verfahrensprogramm des Labors auf, das Transsexualität als erklär- und behandelbare Erscheinung, an die sich verschiedene Theorien und Forschungen heften, betrachtet. Im Alltag werden "Transsexuelle" als ,eigenartig", ,nicht normal", "homosexuel//lesbisch" und möglicherweise als "Transvestiten" eingestuft. Die gesteigerte Definitionsmacht ergibt sich auch aus dem Zusammenwirken der Verbundteile, zwischen denen das Untersuchungsobjekt zirkuliert und von denen es die entsprechende Neuartikulation erfăhrt.

Dieses Labor stellt ein Beispiel für den Fall einer Reparaturwissenschaft dar, d. h. einer Wissenschaft, die, durch gesellschaftliche Reparaturanliegen veranlaßt, in erster Linie Normalisienngsleistungen erbringen soll. Hierbei erscheint die wissenschaftliche Betrachtung und Analyse diesen Leistungen neben- oder auch nachgeordnet. Wissenschaft ist Begjeitforschung furr gesellschaftliche Reparaturprozesse, das Labor ist ein diesen Prozessen angeheftetes Labor. Ein exemplarisches Beispiel für solche, in gesellschaftliche Prozesse eingeklinkten Wissenschaften ist die Medizin. Das wissenschaftliche Objekt, z.B. die Heilung einer Krebsform, entspricht gleichzeitig der Wiederherstellung einer Normalform (,Gesundheit"). Durch die Anheftung des Labors an NomalisierungspTO- zesse sowie die damit verbundene Inkorporation gesellschaftlicher Institutionen (z. B. des Amtsgerichts) in das Labor wird im übrigen nichts dem Zufall überlassen: das Labor sorgt sozusagen selbst fir die Übertragung einer wissenschaftlichen Tatsache, der parallel etablierten und beforschten Transsexualität, in eine gesellschaftliche, dem im Alltag anerkannten anderen Geschlecht.

\section{Das Labor als Zeichenprozeß}

Der Prozeß der Laboratorisierung einer Wissenschaft ist ein Übergang zu einer Erzeugungslogik, wobei dieser Prozeß, wie die obigen Beispiele andeuten, verschiedene instrumentelle Formen annehmen kann. Objekte der Erzeugungsprozesse im Labor sind mun Zeichen. Die Loslösung von Untersuchungsobjekten aus ihrer "natürlichen" Umwelt und deren Neukonstitution im Labor verläuft uber und resultiert in Zeichen; Laboratorien sind materiale Einrichtungen, die Zeichen prozessieren Die Verarbeitungsprozesse des Labors sind immer auch Signifikationsprozesse, $d$. h. Prozesse, in denen Zeichen generiert und deren Referenz bzw. Bedeutung konstituiert werden. Man kann das Labor als Ort ansehen, durch den ein Strom von Zeichen fließst; etwas thnliches haben Latour und Woolgar (1979) gemeint, als sie das Labor als Ansammlung von ,inscription devices", d.h. von Aufzeichnungsmaschinen, bewertet haben. Aufzeichnungsmaschinen sind Apparaturen, die Aufzeichmungen in Form von Zahlen, Graphiken, plots u. ä. als Ergebnis produzieren. Aber die Zeichenarbeit des Labors beschränkt sich nicht aff die Nutzung solcher Maschinen. Das Labor ist nicht nur ein Au/żeichnungssystem zur schrifflichen Fixienung von Ergebnissen bzw. zur Herstellung von Permanenz und Zirkulierbarkeit, die gemeinhin mit Schriftlichkeit assoziiert werden. ${ }^{16}$ Es ist im weiteren Sinn ein Zeichengenerierungs- und Verarbeitungssystem. Das Labor beschättigt sich mit einer Zeichenrealität, wobei die Problematik genau darin besteht, daß sowchl die Zeichen als auch deren Sim bzw. Referenz im Labor konstituiert werden müssen.

${ }^{16}$ Siche dazu z. B. Bourdleu (1976) bzw. Latours Begriff von "itnmutable mobiles", von mobilen, unveränderbaren visuellen Darstellungen in der Wissenschaft (1987). 
Untersuchungsobjekte werden im Labor als ,irreale Gegenstände" ${ }^{\text {"L7 }}$ konstituiert. Dies sind Gegenstände, die sich nicht unproblematisch beobachten lassen und nur indirekt gehandhabt werden können. Irreale Gegenstände sind z.B. die gesuchten $\mathrm{W}$ und $\mathrm{Z}^{\circ}$ Partikel der von uns gegenwärtig beobachteten Teilchenphysik, aber auch die Genelemente und Geneffekte der Molekularbiologie, die "Transsexualität" eines nach Geschlechtswandel strebenden Untersuchungssubjektes der Sexualwissenschaf, oder das "implizite Wissen" eines mit Mitteln der Künstlichen Intelligenz modellierten Experten. Irreale Gegenstände werden durch Zeichen zugänglich und sichtbar gemacht Hierbei kann es sich wie in der Teilchenplysik darum handeln, Apparaturen zu konstruieren, die Objektspuren ,perzipieren" und registrieren, und diese in darstellbare und analysierbare Zeichen transformieren. Oder es kann sich darum handeln, mit Hilfe von Apparaturen die Präsenz von $\mathrm{Ob}-$ jektspuren zu rekonstruieren, $d$. h. Indikatoren für den Untersuchungsgegenstand anhand von $\mathrm{Ob}$ jektäußerungen zu formieren. Sexualwissenschaft und Künstliche Intelligenz setzen hierzu eine Gesprächsapparatur ein (befragen das Objekt) oder rekonstruieren ihren Gegenstand aus anderen Zeichen, die das Objekt setzt (z. B. aus den Schriften von Experten). In jedem Fall ist es ein Ge we be von Zeichen, aus dem sich im Labor die Realităt der Objekte konstituiert.

Hierbei können verschiedene Zeichenformen unterschieden werden (vgl. Amann und Knorr Cetina 1988 a): die bekannteste Form ist sicherlich das Bild bzw. die graphische Darstellung, also Abbildungen, die in zweidimensionaler Form an verschiedenen Stellen von Laborprozessen auftauchen. Meist haben die Proto-Daten des Labors diese Form, aber auch das schließlich veröffentlichte "Beweismaterial" und die Materialien, die zur Kontrolle von stattgefundenen Reaktionen und Abläufen im ,Schnellverfahren" eingesetzt werden. ${ }^{1 \mathrm{~S}}$ Von diesen Abbildungen unterschieden werden kōnnen verkörperte Zeichen, etwa die chemische Reaktion in einer Glaspipette in der Molekulargenetik oder das Lichtsignal in einer optischen Faser in der Teilchenphysik. Im erstgenannten Fall kann etwa der Zustand einer Plasmidpräparation an gewissen Zeichen abgelesen wer-

${ }^{17}$ Dies ist der bezeictmende Auscruck eines Ptysikeis fir die Objekte der Physik.

${ }^{18}$ Z.B. durch sogenamte „Schnellphotos" (Polaroidphotos) von Verfahrensreaktionen. den, wern man das Reaktionsgefä gegen das Licht hält und inspiziert; im zweiten Fall muß das Lichtsignal zunächst in ein analoges und dieses in ein digitales Zeichen transformiert werden, bevor ein Identifizierungsversuch vorgenommen werden kann. Eine dritte Variante von Zeichen sind, ,zenisch": hier ist es der Kontext, die „Szene", die als Zeichen gewertet oder auf Zeichen hin inspiziert wird Die Schulung eines Wissenschaftlers bestett nicht unwesentlich darin, die verschiedenen, fur bestimmte Laborprozesse relevanten Zeichen $\boldsymbol{e}$ kennen zu können und auf sie achten zu lemen Hiermit ist auch gemeint, verschiedene Realităten des Labors als Zeichen setzen zu lemen.

Hierzl ein Beispiel. Die Sexualwissenschaft ist, soweit sie von Psychoanalytikern betrieben wird, eine Wissenschaft, deren Signifikationsprozesse besonders leicht zugänglich erscheinen. Analytiker konstruieren im Bestreben, an die irrealen Gegenstände psychischer Realităt heranzukommen, die Verhaltensweisen ihrer Untersuchungsobjekte (Personen) als Zeichen. So z. B. das Zu-spat-kommen eines Patienten, der als Untersuchungsgegenstand in das Labor der Sexualwissenschaft eintritt. Oder die Sitzhaltung dieser Patienten während des analytischen Gesprächs, ihre Kleidung, ihr norverbales Verhalten, die Tatsache, daß sie - und zu welchem Zeitpunkt sie - eine Zigarette anzinden Analytiker locken überdies Reaktionen der Untersuchungsobjekte hervor, die sie als Zeichen auffassen. Alle körperlichen und sprachlichen „Äußerungen" einer Person können, wie es scheint, in Hinblick auf die untersuchte Realität Signifikanz als Zeichen annehmen. Signifikanz als Zeichen, das interpretiert werden muß und das seine Bedertung aus seiner Neubewertung und Neueinordnung im Rahmen psychoanalytischer Methoden und Kodierformeln erhălt.

Auch die Teilchenpyhsik konstituiert und verarbeitet eine solche Zeichenrealität. Die derzeitige Suche nach dem top quark ist die Suche nach der "signature" eines Teilchens, dessen Existenz nur aus von ihm hinterlassenen, problematischen (ungewissen) Zeichen rekonstruiert werden kann Zeichenverarbeibungsprozesse in der Teilchenplysk sind Prozesse der Ermöglichung (durch immer größere Collider und sensiblere Detektoren), der Transformation (durch Detektoren und ,data acquisition" Programme) sowie des Vergleichs und der Evaluierung der Eigenschaften solcher Zeichen (ebenfalls durch Programme), die fir Teitchen stehen. Die mit einzelnen Experimenten gleichzusetzenden Detektoren stellen die Folien 
dar, auf denen die gesuchten Teilchen ihren "Schriftzug" hinterlassen sollen. In der von uns untersuchten Molekularbiologie stellen die Gele, in denen elektrophoretische Trennungen von Reaktionsgemischen stattfinden, ein Äquival ent solcher Folien dar, wobei hier nicht Teilchen sondern die Spuren von RNA- und DNA-Fragmente interessieren.

Allgemein kann man sagen, da $B$ die Signifikationsprozesse des Labors, d.h. die Behandlung und Generi erung von Laborrealität als Zeichenrealităt, einem ProzeB gleichkommt, bei dem die Bedeutung der unterstellten Zeichen selbst problematisch erscheint. Die Zeichen des Labors sind vielfach Zeichen noch ohne "Sinn" bzw. "Referenz". Ein Großteil der Zeichenarbeit des Labors besteht genau darin, die Bedeutung bzw. Referenz der unterstell ten und "gesehenen" Zeichen zu fixieren, Zei chen sind im Labor also nicht unproblematisch lesbar; sie stellen ein "Etwas" ${ }^{19}$ dar, das in ein Objekt transformiert werden muß.

\section{Der Dialog als Verfahren}

Zeichen stehen für Referenzobjekte, sie sind nicht mit diesen identisch. Die Zeichenform der Laborrealität muß genau deshalb betont werden, weil sie auf die Möglichkeit des Auseinanderkiaffens von Zeichen und Referenz verweist. Im Labor wird diese Möglichkeit zur Routineerfahrung, Es ist das Phannomen der "missing reference", oder im erweiterten Sinn der fehlenden und unklaren Bedeutung, das den Zeichen des Labors ihre charakteristische Ausprăgung verleiht. Interessant ist nun, daß die eingangs erwähnten sozialen und alltäglichen Praktiken, die die Wissenschaft im Labor für ihre $Z$ wecke instrumentalisiert, u.a. genau dann zum Einsatz kommen, wenn es um die Bedeutungskonstitution der "Objekt-losen" Zeichen des Labors geht. Welche Praktiken sind hier gemeint?

19 Vgl. Sacks' Beschreibung des in Gesprächen vorkammenden "Etwas" (Sacks Ausdruck ist „It"), das produziert und verstanden wird, bevor es durch Sinn brw. Referenz bestimmt wurde. Das Sadks'sche „It" ist ein unvollendetes, vages. Die Zeichenarbeit des Labors beschafftigt sich mit der Fertigstellung van solch urvoll endeten Proto-Objekten. Vgl. dazu auch Garn'nkel, Lynch und Livingstons Beschreibung des, n'nishing offs" eines wissenschaftlichen Objekts am Tage seiner Entdeckung (1981).
Naturwissenschaftliche Tătigkeit wird seit langem mit instrumenteller Tătigkeit gleichgesetzt. Nach akzeptierten Auffassungen begann die Naturwissenschaft im 17. Jahrhundert, sich immer komplexerer technischer Instrumente zu bedienen. Durch diese Instrumente wurden, wie historische Studien vertreten (Kutschmann 1986), die Sinnesfunktionen des Wissenschaftlers ersetzt und das Labor zu einem Ort technisch-instrumentellen Handelns. Im Laboralltag stelli man jedoch schnell fest, daß zu den Instrumenten des Labors nicht nur Apparaturen, Maschinen und andere Einrichtungsgegenstände gehören, sondern z.B. auch eine $\mathrm{Ge}$ sprächsmaschinerie, d. h. eine "Hardware" von interaktiv realisierten Erzeugungsverfahren.

Einzelne Laborformen unterscheiden sich $u$. a. dadurch, wie sie Mündlichkeit, Schriflichkeit und Körperlichkeit behandeln. Mundliche Interaktion, Vertextung und verkơrperte Tătigkeit sind Aspekte allen Forschungshandelns. Laboratorien unterscheiden sich jedoch dahingehend, ob und in welcher Weise sie diese Handlungsfoimen in Erzeugungsinstrumente für wissenschaftiche Ergebnisse transformieren. Diese Erzeugungsinstrumente kommen, soweit es sich z. B. um Interaktionsapparaturen handelt, genau dann zum Einsatz, wenn es um die Bedeutungskonstitution der "Objekt-10- " sen" Zeichen des Labors geht. Interaktionsapparaturen sind routinisierte technische Verfahrensweisen; sie sind Werkeuge im Umgang mit Zeichen ähnlich wie die technischen Geräte des Labors .Werkzeuge bei der Produktion von Zeichen darstellen. Den Maschinen des naturwissenschaftichen Labors scheint die Generierung und Darstellung, die Selektion (z.B. durch "trigger") und statistische Aufbereitung vieler Laborzeichen vorbehalten. Die interaktiven Apparaturen mündlicher u.a. Erzeugungsinstrumente setzen im naturwissenschaftlichen Labor dort nahtl os an, wo die Arbeit technischer Gerăte endet: Sie sind u. a. auf den Zusammenhang zwischen Referenzobjekt und Zeichen, also auf den ProzeB der Anknüpfung eines Zeichens an ein (Natur)objekt, spezialisiert. Die Verkopplung zwischen technischem Gerät und Diskurs ist eng; die innovativen Ergebnisse des Labors sind das Resultat von "Machine-discourse Couples". ${ }^{20}$ In der von uns untersuchten Molekularbiologie im Bereich der Untersuchung transkriptioneller Enhancer stellt sich mit jeder Autora-

${ }^{20} \mathrm{Vg}$. den anders definierten Begiff eines ,hardwarediscourse couples" bei Watchirs und Schuster (1987). 
diographie $^{21}$ (s. Abbildung 1), die experimentelle Daten beinhaltet, die Frage, welchen Objekten (DNA - bzw. RNA-Fragmenten) die erscheinenden Schwärzungen auf dem Film zuzuordnen sind. Genau hier setzt eine Gesprächsapparatur ein, die im folgenden genauer analysiert wird. Die Gesprăchsapparatur findet sich ebenso in der Teilchenphysik und anderen, bisher untersuchten Disziplinen. $^{22}$ Im folgenden einige Beispiele aus der Molekularbiologie.

Das răumlich eingebundene „Innen"labor der Molekularbiologie mit seinen offenen, über-schaubaren Arbeitsbänken und offenen Türen ist ein in extremer Weise mündlich strukturiertes Labor. Mündlichkeit charakterisiert alle Kontakte zwischen den Teilnehmern, die nicht zuletzt durch sie zu einer "Gruppe" zusammengefügt werden. Das molekularbiologische Labor hat sozusagen (Gruppen) Mitglieder, nicht nur Teilnehmer. Charakteristikum der Mündlichkeit ist ihre Informalität: zwar existieren formale Gelegenheiten für Gespräche wie Seminare und Gruppenbesprechungen, der Großteil der Kontakte findet jedoch ,zwischen Tür und Angel", über die Arbeitsbank hinweg und um Apparaturen, statt. Clifford Geertz (1973) und Latour und Woolgar (1979) haben Wissenschaftler als ,Zwanghafte" Schreiber charakterisiert. Wissenschaftler müssen ihre Verfahren und Beobachtungen ständig niederschreiben, damit die Informationen nicht verloren gehen. Wenn das richtig ist, so sind viele Wissenschaftler aber um so mehr zwanghafte „Schwătzer" - zumindest gemessen an der Zeit, die in bestimmten Laboratorien anf Gespräche verwendet wird und ein Vielfaches der Schreibtätigkeit ausmacht. Räumliche Anordnungen spielen hierbei eine Rolle, etwa große Laborräume mit vielen Arbeitsbänken oder chronische Raumknappheiten, die dazu fuhren, daß Schreibtische und Arbeitsbannke im selben Raum zusam-

${ }^{21}$ Autcradiographien werden durch radioaktiv markierte DNA- oder RNA-Fragmente erzeugt, die in einem Elektrophorese Gel separiert wurden, auf dem em Röntgenfilm exponiert wurde. Im Labor entsprechen Autoradiographien Folien, auf denen geschwärate Banden auftreten. Die untersuchte Gruppe beschattigt sich mit der Aufklänung von regulatorischen Genelementen (z B. ,cnhancem" und ,promotem"), die bei der Transkription von DNA in RNA die Transkriptionsaktivităt erhöhen kömen und die daher fir das Verständnis normalen und a-normalen Zellwachsums ausschlaggebend sein können

${ }^{22}$ Beispiele liegen uns z.B. auch aus der Atomphysik vor.

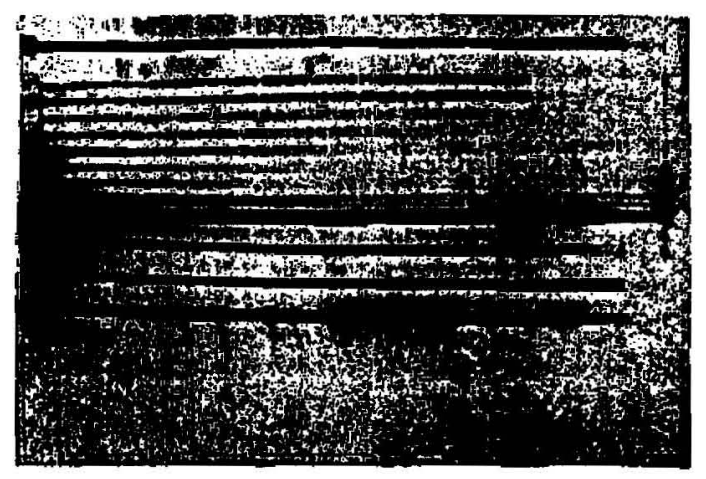

Abbildung 1 Beispiel einer im Labor inspizierten Autoradlographie.

mengedrängt werden mũssen. In der Molekularbiologie handelt es sich meist um "kleinräumige" Apparaturen und Tătigkeiten, die sich anders als Rechnernetze u. ä. aff wenig Raum beschränken lassen.

Mündlichkeit wird im Arbeitsbanklabor zum technischen Instrument gesteigert: in Form von shop talk, von technischen Gesprächen, ist sie Instrument der Erzeugung von Wbsen ous dem Händischen und Apparativen des Labors. Im molekularbiologischen Labor ist das technische Gespräch zwischen den Teilnehmern Mittel des "Lesens" und der Interpretation der besagten Schwärangen auf Autoradiographien und von anderen ProtoDaten, die von techmischen Apparaten erzeugt werden und die in Abbildung 1 illustriart werden In diesen Gesprächen werden die unklaren Spuren diverser Laborinstrumente erkennbar und identifizierbar gemacht, sie werden interpretiert und - mit Hilfe gleichbleibender Gesprächsroutinen - in lesbare "Daten" transformiert (vgl. Amann und KnorrCetina 1988 b).

Ein erstes Beispiel einer solchen Routine ist die Verfahrensimplikatur ${ }^{l}$ *, Das Dialogmuster wird dazu verwendet, um aus sturmmen experimentellen Ergebnissen anhand einer Erforschung der Verfahren, durch die die Ergebnisse erzeugt wurden, nicht-offensichtliche Schlußfolgerungen herzuleiten. Es besteht aus einer Serie von Parsequenzen (Frage-Antwort oder Behauptung-Bestätigung), die die Biographie des Phänomens und seine Reaktionen efforschen. Das Muster kann durch eine Problemdarlegung oder einen Bericht eröffnet

${ }^{23}$ Der Ausctuck, ,Implikatur" ist an das Grice'sche Korzept der corversational impiicature (1975) angeldurt. Vgl auch Cicarrel 1978 
"werden und wird in der Regel durch eine Schlußfolgerung in Fom einer Interpretation (,das heißt", „das bedeutet") oder einer Handlungsempfehlung (, ich würde ...", ,du mußt...") geschlossen. Im folgenden Beispiel rekonstruieren die mit $\rightarrow$ angegebenen Beiträge die Verfahrensgeschichte des Phanomens:

\section{(190904 84z640)}

$640 \mathrm{Fr}$ und gestem hab ich durch die Ro zufällig gehört daß GTC vielleicht doch nicht so ganz das wahre ist, 0 daß die Ausbeute daß die Qualităt zwar gut ist, das hab ich von der Sy gehört aber die Ausbeute ist nicht so gut

644 Ma die Qualität ist gut aber

$645 \mathrm{Fr}$ jaja

$646 \mathrm{Ro} \mathrm{mhm}$. Weil es

-) 647 Ma O ohne neo'oder mit neo'

648 Ro ohne neo aber mit th $2 \%$ FCS

$\longrightarrow 649 \mathrm{Ma}$ oh ja, langsam jetzt. Der To hatte doch mal cotransfiziert mit PSV2 neo

651 Ro $\mathrm{mhm}$ und diesen MSV-LPV

$\rightarrow 653 \mathrm{Ma}$ davon hat er dann das Gemisch hochgezogen, oder wie war das'

- 654 Ro ja, und davon hat er n parr Klone gepickt

$655 \mathrm{Ma} \mathrm{o.k}$.

$\rightarrow 656$ Ro und ich hab das jetzt nochmal gemacht ohne neo und parallel LPV in $\mathrm{pBr}$. Also nur LPV

$\rightarrow 658 \mathrm{Ma}$ du hast also im Prinzip auch wieder

$659 \mathrm{Ro} \mathrm{mhm}$ dieses MSV-LPV und nur LPV

- $\rightarrow 660 \mathrm{Ma}$ und hast die transfiziert anf NIH3T3

$661 \mathrm{Ro} \mathrm{mhm}$

$\Rightarrow 662 \mathrm{Ma}$ und hast foci (?) gepickt

$\rightarrow 663$ Ro (und auch?) ((unverständlich))

664 Ma o. $\mathrm{k}$

$\rightarrow 665 \mathrm{Ro}$ und hab die in $2 \%$ Serum hochwachsen lassen

$666 \mathrm{Ma} \mathrm{ja}$, und was kormmt daraus'

$\rightarrow 667$ Ro und da sind unheimlich viel gestorben und ein paar sitzen gebheben und haben auch sone Art foci (2) gebildet

$668 \mathrm{Ma}$ aha

$\rightarrow 669$ Ro und davon hatte Si so firf bis zehn Klone gepickt

670 Ma sehr gut, sehr gut

$\rightarrow 671$ Ro und die lassen wir jetzt hochwachsen und dann werd ich halt noch $\mathrm{n}$ blot machen
$673 \mathrm{Ma}$ mach unbedingt $\mathrm{n}$ Immunofluoreszenz, direkt kannst jetzt schon machen, die Woche noch ((Etc.))

Man beachte, daß die Schlußfolgenung (Z. 673) am Ende einer solchen Gesprächsrunde nicht alf die Eröffnungsäußerung, etwa eine Problemdarlegung (Z. 640ff.) einzugehen braucht. In der Tat antwortet sie meist auf die Rekonstruktion der Verfahrensgeschichte, die zwischen dem sequenzauslösenden Beitrag und der Schlußfolgerung liegt Es ist, als ob sich die Teilnehmer darauf verlassen, daß die Entwicklung ihrer Interaktion eine Schlußfolgerung produzieren wird - oder genauer Markmale des Phănomens produzieren wird, die eine Schlußfolgerung nahelegen. Die Rekanstruktion, die die Teilnehmer durchführen, bestimmt fïr sie die Art des Problems ebenso wie dessen Konsequenzen in Hinblick anf weiterfuhrende Arbeiten. So hat im obigen Transkript die resultierende Handlungsempfehlung (Z. 672) weniger mit dem Eingangsproblem $\mathrm{zu}$ tun (daß eine bestimnte Methode nicht gut funktioniert, Z. 640), als damit, $\mathrm{da} B$ Ma die Testresultate in seinen Vortrag auf einer in der folgenden Woche stattfindenden Konferenz einbauen möchte, wie spätere Äußerungen Ma's bestätigen ${ }^{24}$ - eine Möglichkeit, die der Verlauf des Gesprächs nahegelegt hatte. Das Muster folgt weder dem Standardmodell deduktiven Argumentierens noch dem Problemlösungsmodell. So kann das Gespräch zur "Lösung" eines „Problems" führen, das man vorher nicht hatte, wathrend das gesprächsinitiierende Problem lösungslos bleibt. Das Muster entspricht wohl am ehesten der Logik historischer Forschung, d.h. der Rekanstruktion idiosynkratischer Ereignisse Die Teilnehmer verwenden eine Technik ähnlich der des narrativen Interviews (Schütze 1970), um die konkreten Geschehnisse in ihrer historischen Abfolge hervorzulocken - sie scheinen nicht interessiert an einer fertigen Problemdiagnose oder an den Theorien der Konsultierten „über" das Phänomen. Entsprechend stellt sich das „Durchdenken" des Problems als das interaktiv erzeugte Produkt der historischen Nachforschungender Teilnehmer dar - und nicht als Ergebnis der Kopfarbeit eines Beteiligten.

\footnotetext{
${ }^{24}$ Nach einigem hin und her daruber, wann der Immunofluoreszenztest gemacht werden kann, meint Ma auf Z. 685, daß er die Sache (bei entsprechendem Testresultat) irgendwie (in seinen Vortrag) einbauen könnte. Und auf Z. 689 erklärt er, daß er damit zwei Punkte (im Papier) machen kơnne, die er in der Fodge ausfuhrt.
} 
Ein weiteres Dialogmuster, das immer wiederkehrt, verfahrt oppositiv. Es handelt sich um Streitgespräche, bei denen die Teilnehmer ihre Uneinigkeit dazu benutzen, relevante und neue (bisher nicht offensichtliche) Merkmale des Phånomens hervorzulocken. Solche Gespräche sind also nicht einfach funktionslose Ärgernisse, die mit der Streitsucht einzelner Wissenschaftler zu tun haben. Auch bei diesen Gesprächen handelt es sich um technische Instrumente, und zwar um Instrumente der Induktionsproduktion, etwa im Dienste der Interpretation von Proto-Daten. Im folgenden, oppositiv verlaufenden Gesprächsausschnitt geht es darum, ob es sich bei bestimmten Banden auf einem Autoradiographiefilm um die Probe oder um unspezifische Starts handelt:

\section{(140106 85p66)}

44 Fr das Gegenargument ist das, daß diese RNA-Starts auf der Hohe vom Marker laufen. Korrekt (laufen)

46 Wa wenn Du jetzt sagen willsch, daB du plusminus 5 siehsch, da fang ich abers lachen an

48 Fr das sind, .je länger die sind, de sto,...

49 Wa du sagsch, daß des hier early early und zwei $u$.. fuinf $B$ asen weiter ist

51 Fr nee, erstens lass ich meine Gele länger laufen

52 Wa haha

53 Fr außerdem sind die bei mir 309 und das ist 305 bis 310

((zeigt auf seinen Film))

55 Wa also, die laufen ja auch falsch

56 Fr die laufen auf einer Höhe

57 Wa ((ironisch)) 305 und 309 laufen auf einer Höhe, ganz richtig

58 Fr du ((wird ungeduldig)) das hier oben ist 520

59 Wa mhm

60 Fr und das wäre danach> wenn du das als 404 nimmst, ungefähr 450. Das heißt, du würdest damit

62 Wa nee, das kann genausogut 480 sein. Da fangts doch an..

63 Fr ja du wurdest aber def.. dadurch fordern, daß du 70 .. 50 bis 70 Basenpaare Unterschied hast durch das Sal z

65

Wa Mann, des hat doch was mit der Laufstrecke zu tun! ((Etc.))

Solche Dialogformen sind Erzeugungsinstrumente wissenschaftlicher Objekte in dem Sinn, daB sie durch die Schlußfolgerungen, die sie interaktiv produzieren - die unklaren Spuren experimenteller Verfahren in bestimmter Weise interpretieren. Sie verweisen gleichzeitig auf die Prothesenstruktur wissenschaftlichen Denkens im Labor. Das Gespräch dient als Denkprothese genauso wie es im Falle von Bildanalysegesprāchen (Knorr Cetina und Amann 1988) als „Sinnesprothese" herangezogen wird. Technische Gespräche sind aber nicht nur Mittel der Gewinnung von Daten aus ProtoDaten, sie sind auch Mittel des Lesens der veröffentlichten Daten und Papiere, der Protokolle und Methodenvorschriften von Wissenschaftlem, die nicht Labormitglieder sind. Schriftliche Dokumente werden im Arbeitsbanklabor somit vermündlicht, wobei es im Falle von Papieren hierfür auch die formalen Einrichtungen von wöchentlichen Literaturseminaren gibt. Sie werden in „eingerichteten" und spontanen Diskursen, die das gesammete Wissen, die Einschätzungen und Bewertungen von anderen Gruppenmitgliedern mobilisieren, dekonstruiert und neu prozessiert, $d$. h. als Objekte des Labors rekonstruiert.

\section{Der Körper als Instrument}

Die Gesprăchsapparaturen der Naturwissenschaftler sind nicht die einzigen der sozialen Welt „entnommenen" Praktiken, die sich die Wissenschaften als Instrument für ihre Zwecke verfügbar machen. Eine weitere, nicht weniger interessante Verfügung bezieht sich auf den Körper des Wissenschaftlers. Wie erwähnt wurden nach vorherrschender Auffassung die Simnesfunktionen des Wissenschaftlers ab dem 16. Jhdt. in zunehmendem Umfang durch Instrumente verdrängt. Hierbei wird vor allem auf di e "Verlångerung", Verbesserung und schließlich Ersetzung der Wahmehmung des menschlichen Beobachters durch optische Verfahren (z. B. Galilei's Teleskop) verwiesen. Historische Arbeiten vermuten eine weitere Ursache für die Ersetzung der Sinnesfunktionen des Wissenschaftlers durch Instrumente im Versuch, Vorstellungen einer Objektivierung wissenschaftlicher Erkenntnis durch Ausschließung von Täuschungen und Irrtümern in die Praxis umzusetzen, die nach zeitgenössischen Auffassungen mit den spezifischen Beschränkungen menschlicher Sinnesorgane sowie mit der bei Sinneserkenntnis gegebenen "Teilhabe" des menschlichen Beobachters an den Erkenntnisobjekten zu tun haben. Die

${ }^{23}$ Für eine detaillierte Darstellung dieser Argumentation sieh e Kutschmann (1986). 
moderne Naturwissenschaft tritt aus dieser Analyse als „leibfreie", die modeme Natur als "desanthropomorphisierte", und der Körper des Wissenschaftlers als ein "Schattendasein" führend hervor. ${ }^{25}$ Bei der Beobachtung der Laborpraktiken moderner Wissenschaftler zeigt sich allerdings, daß sich diese Vorstellungen unbeschadet der Einfilhrung technischer Instrumente in die Naturwissenschaft nicht aufrecht erhalten läßt, wiewchl sie den programmatischen Aussagen und ideellen Vorstelhungen bahnbrechender Wissenschaftler im 16./17. Jhdt. durchaus entsprechen mag. Das naturwissenschaftliche Labor bemächtigt sich vielmehr des Körpers des Naturwissenschaftlers und setzt diesen - in zugerichteter Weise - gerielt für bestimmte Zwecke ein. Insbesondere erscheint auch die Objektivität der erzielten Resultate, d. h. ihre Bewertung als Vertrauens- und glaubwürdig, an körperliche Erfahrung gebunden.

Die „Bemächtigung" des Kơrpers ist hierbei zunächst durchaus wơ̈tlich zu verstehen. Die Übungen, denen sich Nachwuchswissenschaftler im Labor (und in den vorangehenden Lehrlaboratorien ihrer Universitătsausbildung) unterziehen müssen, sind immer auch körperliche Schulungen, Disziplinierungen $^{20}$ im Sinne disziplin-spezifischer Einschleifungen von Körperhaltungen, Sichtweisen, Hantierweisen, speziellen Geschicklichkeiten ebenso wie spezifischen Ertragungsfăhigkeiten. Letztere beziehen sich im einfachsten Fall bei den untersuchten Hochenergiephysikem aff handwerkliche Geschicklichkeiten, auf Nachtarbeit, 12-16stündige Arbeitszeiten sowie Abrufbereit' schatten während eines "data-runs", und auf die Bereitschaft zur Durchführung langer Computertătigkeiten. Das Ausmaß der erforderlichen körperlichen Fähigkeiten wird vor allem dann offensichtlich, wem einzelne Teilnehmer sich als ,im Labor unbrauchbar", als "Theoretiker", als nicht den nötigen ,touch" habend, „um ein Experiment zum Laufen zu bringen", ${ }^{27}$ herausstellen. Leiter von Forschungsgnuppen beobachten die entsprechenden Fortschritte von Diplomanden und Doktoranden und wählen für weitere Arbeiten diejenigen, die ,im Labor geschickt" erscheinen und mit den entsprechenden Apparaturen „etwas anfangen" können, aus.

\footnotetext{
${ }^{26} \mathrm{Vgl}$. Foucaults Analysen des "gel ehrigen" Körpers, der nach Foucault im 19. Jhdt. Ziel und Resultat von Dl sziplinierungstechniken war (z. B. 1979).

27 Si ehe dazu auch das Beispiel in Krüclc (1988).
}

Der Zurichtung des Körpers des Wissenschaftlers folgt sein Einsatz im Labor. Hierbei erscheinen zwei Verwendungsweisen auffallend: 1) die Verwendung des Körpers als Meßinstrument und Datenverarbeitungsmittel; und 2) der Einsatz des Körpers als Archiv und Depot von Erfahrung. In beiden Făllen ist der Körper ein stummes Instrument. Sein Einsatz efolgt charakteristischerweise anstelle von verbalen - oder mentalen - (R ekonstruktionen eines Geschehens. Die einfachste Illustration dafür, daß Wissenschaftler ihren Körper als Informationsverarbeitungsinstrument einsetzen, ist dann gegeben, wenn diese darauf bestehen, das interessierende Phänomen "face-to-face" in Augenschein zu nehmen. Interessant hierbei ist, daß auf ,persönlicher" Konfrontation insistierende Wissenschaftler ihrem Denk- und verbalen Aufklärungsvermögen offenbar mißtrauen und anstèle dessen ihre Sinne bei der Identifikation und Prozessierung relevanter Informationen favorisieren. Mit anderen Worten, es wird unterstellt, daß es nicht möglich sei, das Problem verbal oder mental durchzuräsonieren. Um zu wissen, was man denken oder sagen soll, muß man sich zunächst in die relevante Situation plazieren. Dem Körper wird zugetraut, das zu identifizieren, was Gesprächsapparatur und Verstand nicht antipizieren können. Die Teilnehmer greifen hier auf die cartesianische Trennung zwischen „Körper und Geist" zurück, wobei sie dem Körper offenbar Priorität einräumen.

Das Substitut, das körperliche Meßverfahren für dialogische und andere Verfahren darstellen, wird im bisher untersuchten naturwissenschaftlichen Bereich nicht thematisiert. Anders ausgedruckt, es existiert in diesen Wissenschaften keine methodische Kodifizierung, keine systematische Beschreibung der oder schriftliche Anleitung zu den bei solchen Meßverfahren involvierten körperlichen Reaktionen, Vorgängen und (Meß)Einstellungen. Das Funktionieren des Geräts des Körpers außert sich lediglich darin, daß das Gerät, z.B. die körperliche Wahrnehmung, Ergebnisse produziert, die allerdings meist technische Formulierungen darstellen, und in keiner Weise auf das Meßverfahren selbst Bezug nehmen. Die Meßtheorie des Gerătes des Körpers beschrănkt sich darauf, die Notwendigkeit körperlicher Präsenz bzw. körperlicher Durchführung fir bestimmte Zwecke zu postulieren. Es ist eine Theorie des ,selbst sehen" und ,selbst machen" müssens, die sich vor allem in entsprechenden Ratschlägen und Anweisungen an jüngere Wissenschaftler manifestiert. Sie zeigt sich auch in zirkub'erenden „,atrocity" stories, in „Hör- 
ror" geschichten von geschehenen oder möglichen Unglücksfällen, die auf die Nichtbeachtung des „face-to-face" Postulats zurückgefuhint werden.

Im medizinischen Lab or der Transsexuellenforschung entspricht dem genannten "face-to-face" Postulat ein rudimentäres Empfindungsvokabular, mit dem auf körperliche Meßverfahren Bezug genommen wird. Im Vergleich zum mündlich strukturierten Arbeitsbanklabor der Molekularbiologie überwiegen in diesem Labor körperliche Darstellungen, nämlich die Selbstdarstellung der Untersuchungsobjekte (Transsexuelle; vgl. Hirschauer 1987). Solche Selbstdarstellungen werden nicht nur von den Untersuchungspersonen, etwa im Sinne Goffman's, als Routinebestandteil ihres Alltagsbetragens gesetzt. Sie erhalten epistemische Relevanz dadurch, daß sie von den einzelnen Laborstationen systematisch gefordert, in Augenschein genommen und auf ihren Wirklichkeitsge halt überprüft werden. Bei diesen Überprüfungen begegnen die Therapeuten/Forscher im Zentrum des Labors den Untersuchungsobjekten auf gleicher Ebene: die körperlichen Darstellungen der Untersuchungsobjekte werden mit dem Körper des Therapeuten ,gemessen". Therapeuten setzen ihren eigenen Körper als ganzheitliche Aufzeichnungsinstrumente ein und fragen durchaus theoriegeleitet, welchen "Eindruck" dieses Aufzeichnungssystem aufgrund der körperlichen Darstellungen des Untersuchungsobjektes registriert Hierbei wird ein rudimentäres Empfindungsvokabular verwendet, um diese Eindrücke zu beschreiben. Therapeuten' Forscher stellen z.B. von sich fest, daß sie bestimmte Untersuchungsobjekte ,als etwas" (z.B. als Frau oder Mann) "empfinden", daß sie "etwas an sich und an dem Patienten erleben", daß Personen "keine Gestalt" gewinnen, ,nicht greifbar" oder "überzeugend" sind, daß sie deren Empfindungen ,Zu spuren" bekommen u. ä. mehr. Die Selbstdarstellungen des Untersuchungsobjektes sind Proto-Daten, die Bezugnahme auf das eigene "Gefühl" des Therapeuten/Forschers der Versuch, diese Daten in selbstdistanzierender Weise zu identifizieren und zu analysieren. Der in situ registrierte „Eindruck" sowie dessen nachträgliche reflexive Analyse bestimmen dann den weiteren Verlauf der Behandlungsprogramme, die Therapeuten einsetzen. Auch andere Stationen im Laborverbund, z.B. Amtsrichter, bestehen aif der „körperlichen" Inspektion der Objekte, d. h. auf persönlichen Präsentationen des Transsexuellen, wobei die Überprüfung der "Realität" der Geschlechtlichkeit des Transsexuellen dem Simesapparat des Prüfers, dessen „Empfindung", überlas- sen wird. Im übrigen spielt auch bei den Kontakten zwischen den Verbundstationen der Körper eine Rolle, wenn etwa Transsexuelle als ,lebende Beweismittel" zwischen den Stationen hin- und hergeschickt werden.

Die Empfindungsmethode von Therapeuten, Amtsrichtern und anderer Laborteilnehmer hat u.a. den Zweck, schriftlich oder mündlich (z.B. durch das interrogative Verfahren des therapeutischen Gesprächs) erhaltene Information zu überprüfen und zu validieren. Auch hier artikuliert sich die "Sinnesmethode" körperlicher Meßverfahren als "stummes", die Sprache oder reines Denken verweigerndes Verfahren. Wie in den untersuchten Naturwissenschaften wird auch hier dem kärperlichen Meßverfahren Priorităt zugestanden, wern es andere Verfahren ersetzt. Priorität insofem, als die Bewertung der Resultate als Vertrauens- und glaubwürdig an körperlicher Erfahrung festgemacht wird. Korporalität erhălt epistemische Relevanzu.a. dadurch, daß sie auf vielfältige Weise $a l s$ Gorant von Wahrheit erscheint. Ein ,geschickter" Körper ist im Labor ein wichtiger Plusposten bei der Berechnung der Wahrheitsträchtigkeit von Resultaten. Aspekte eines Experiments selbst gesehen - und insbesondere in den Naturwissenschaften auch selbst durchgeführt $a 1$ haben - erscheint als das Kapital, von dem Vertrauen zehrt. Onne dieses Kapital wird die Urteils- und Aussagekraft eines Wissenschaftlers, und mit dieser die Güligkeit seiner/ihrer Resultate, anzweifelbar. Im folgenden Gesprächsauszug beklagt sich ein Naturwissenschaftler in einem von uns untersuchten $\mathrm{La}$ bor über die Euphorie seines Vorgesetzten, der Ergebnisse, die er nicht einschätzen könne, weil ar sie nicht selbst gesehen und durchgeführt habe, dennoch in der ganzen Welt verbreite, wem sie seinen Erwartungen (und Hofflnungen) entsprä* chen:

\section{5 p 221}

(...) Wenn des so ist, wie er sich's denkt, dann (lacht) kann das Experiment noch so beschissen gelaufen sein, (...) Du kanns ihn nicht bremsen, ja? (...) der rennt, der galloppiert durch ganz Europa mit falschen Informationen, ja? Und kein Mensch traut (...) Und des kann ihm nochmal das Genick brechen (...) Und da hab ich halt Angst, daß ihm sowas mal passiert. Ja? Weil er die Experimente ja net selber maxht. Aber ich hab ihn schon so'n paarmal gesehen, wo er mit so Sachen, die so mau! waren, wo du, weißt, wo du selber net dron gestanden bist und gesehen hast wie des gar net war. Der hat in derAbwe- 
senheit das erzahlt, wahrschein... dann ruft er immer gleich noch nach USA an und des weiß dann die ganze Welt!

(Hervorhebungen hinzugefügt)

Vertrauen "haftet" an körperlichen Durchfühnumgen, auch wenn es sich um ,triviale" Tätigkeiten wie das Reinigen von Glasutensilien im mikrobiologischen Labor handelt. Solche und ärnliche Nebentátigkeiten werden um der Vertrauensgarantie willen, die ihnen zugeschrieben wird, zur körperlichen Durchführung empfohlen. Die Situation ist anders, wenn es sich um die Anfertigung eines Computerprogramms, den Bau einer physikalischen Apparatur, die Abwicklung eines Elektrophoresedurchlaufs in der Mikrobiologie, kurz um konstruktive Sequenzen, handelt. Korrelat der Durchführung durch einen Wissenschaftler ist hier die Entwicklung eines korporalen Gedächtnisses, die Nutzung des Wissenschaftlers als verkörpertes Depot händischer und instrumenteller Erfahrung. Der Wissenschaftler, der twa eine physikalische Apparatur selbst entwirft und zusammenbaut, entwickelt ein Verfahrens wissen, das nicht vermind licht oder verschriftlicht wird. Es bleibt „eingeschrieben" in den Körper seines Trägers und geht mit ihm für das Labor verloren, wenn dieser es verläßt (oder muß mühsam neu erworben werden). In der untersuchten Künstlichen Intelligenz weigern sich die Teilnehmer, sich in den Programmcode eines anderen Teilnehmers einzuarbeiten, und ziehen es vor, den Code nea zu formur lieren. Die Qualităt eines Prograrmms wird hier an dessen Leistungen gemessen, und nicht durch Nachvollzug seines Inhalts aberprüf: der Inhalt des Programms eines anderen Teilnehmers gilt praktisch als nicht nachvollziehbar, das verkörperte Archiv, das der Programmautor darstellt, wird als unzugangliches behandelt.

Die Verkörperung von Verfahrenswissenskopital ${ }^{28}$ durch Insistieren auf Selbstdurchführung bei weitgehendem Fehlen entsprechender Dokumentation widerspricht dem der Wissenschaft zugeschriebenen Verschriftlichungszwang. Daran ändert auch nichts die Existenz von Laborprotokollen: Auch Laborprotok olle von Verfahren sind nicht metr als formelhafte Ereignis- und Ergebnisfesthaltungen ohne Versuch zur Verständlichmachung und Begründung des Geschehens. Will ein Teilnehmer den tatsächlichen Ereignisablauf verstehen, so muß er/sie das Geschehen in Interaktion mit dessen

${ }^{28}$ Vgl. den Begriff eines körperlich eingeschriebenen kulturellen Kapitals bei Bourdieu (2. B. 1983),
Beiwohnem rekonstruieren. In gewisser Hinsicht stellen Protokolle - wie auch wissenschaftliche $\mathrm{Pa}$ piere - Außendarstellungen dar, die das Geschehen richt erschließen, sondem verschlüsseln. Als Begnündung für die Notwendigkeit, konstruktive Sequenzen selbst durchführen zu müssen, wird jüngeren Wissenschaftlem ubrigens konsequenterweise das „Verständnis" angegeben, das sie sich so - und nicht anders - erwerben kőnnten.

Der Körper als Depot einer eingeprägten Verfahrensgeschichte muß, um es nochmals zu erwahnnen, in situ in Einsatz gelangen. Er funktioniert, wie man sagen könnte, nur eingespannt in die Situation, deren Kenntnis er in analogen Situationen erworben hat. Im Falle einer selbst gebauten physikalischen Apparatur kann das benötigte, deponierte Wissen etwa erst dann mobilisiert werden, wenn sich dessen Träger in diese Apparatur ,eingeklinkt" hat, sich an ihren Ont und vielfach in ihren Innenraum begeben hat. Dem Abruf dieses Wissens über ein in Erinnenung-rufen aff Distanz wird von den Wissenschaftlem in der Regel das Begeben an den Ort des Geschehens vorgezogen. Es ist, als ob der Körper als Gedáchtnis- und Informationsverarbeitungssystem nur als Teil des Apparats, dessen ,Mitglied" er durch wiedetholten Umgang geworden ist, bestehen könnte. Dieser Situation kommt in der Physik die Paarung zwischen Wissenschaftler und Apparaturen bzw. Apparaturteilen entgegen. Wissenschaffler werden nicht fir bestimmte analytische Vorgänge, die quer zul verschiedenen Apparaturen liegen, für zuständig erklărt, sondem einzelnen Apparaturen (Apparaturteilen) zugeordnet. Sie gewimnen ihre wissenschaftliche Identităt durch die Identifikation mit ,ihren" Apparaturen (vgl Traweek 1988). In der Künstlischen Intelligenz entspricht dieser $\mathrm{Zu}$ ordnung die Paarung von Wissenschaftler und Programm.

\section{Zusammenfassung}

Körperliche Meßverfahren sowie die Verkörperung von Vertrauen und Verfahrenswissen in der Naturwissenschaft gehören ebenso wie die Gesprächsmaschinerie des shop talk zu den interaktiven und verkőrperten Praktiken, die die Wissenschaft aus der sozialen Alltagswelt übemommen und zum Instrument der Erzeugung van Wissen „verdichtet" hat. Mündlichkeit, Körperlichkeit und Schriftlichkeit sind Aspekte allen Forschungshandelns. Einzelne Laborformen unterscheiden sich jedoch dahingehend, ob und in welcher Weise 
sie diese und andere soziale Handlungsformen in wissenschaftliche Instrumente transformieren. Im schriftlich strukturierten Labor der Künstlichen Intelligenz und Informatik, das hier nicht weiter behandelt wurde, ist z.B. eine Instrumentalisierung von Gesprächsroutinen nur in Ansătzen zu beobachten, und Körperlichkeit beschränkt sichauf die Paarung von - und die Nicht-Einmischung andere Teilnehmer in - Einzelwissenschaftler und Programm. Die im vorliegenden Papier illustrierte "Bemächtigung" von Interaktion und Körper durch einzelne Wissenschaften erschöpft nicht das soziale und kulturelle Repertoire, das diesen Wissenschaften ar Verfügung steht. Es bleibt weiteren Arbeiten vorbehalten zu zeigen, welche anderen Komponenten dieses Repertoire (wie z.B. Tratsch und Markt) sich die Wissenschaft al eigen gemacht hat.

\section{Litergatur}

Amann, K./Knorr Cetina, K., 1988a: The Fixadon of (Visual) Evidence. Human Studies II (2-3), Special Issue on: Representation in Scientific Practice, $M$. Lynch und S. Woolgar (Hrsg.) (im Druck)

Amann, K./Knor Cetina, K., 1988b: Werkstattgesprāohe in der Wissenschaft am Beispiel der Molekularbiologie In: H. G. Soeffiner (Hrsg.), Frankfurt: Campus (im Drudk)

Bames B., 1977: Interests and the Growth of Knowledge. London Routledge \& Kegan Paul

Barnes, B.MacKenzie, D., 1979: On the Role of Interets in Soientific Change In: $R$ Wallis (Hrsg,): On the Margins of Science: The Social Construction of Rejected Knowledge Sodological Review Monograph 27. Keele: University of Keele

Bloo, D., 1976: Knowledge and Social Imagery. London: Routledge \& Kegan Paul

Bourdeu, P., 1976: Entwurf einer Theorie der Praxis auf der ethndogischen Grundlage der kabylischen Gesellschaft Frankfiut/M.: Suhrkamp

Bourdeu P., 1983: ökonomisches Kapital, kulturelles Kapital, soziales Kapital. In: R. Kreckel (Hrsg.) Soziale Welt Sonderband 2 ZZur Theorie sozialer Ungleichheiten". Göttingen, 183-198

Goourel, A., 1978: Language and Society: Cognitive, Oultural and Linguistic Aspects of Language Use. Socialwissenschaftliche Annalen 2: 325-359

Collins, H. M., 1975: The Seven Sexes: A Study in the Socidogy of a Phenoraen or the Replication of Experiments in Physics Sociology 9; 205-224 •

Collins, H. M., 1981: Introduction: Stages in the Empirical Programme of Relativism. In: $H$. Collins (Hrsg.): Knowledge and Controversy: Studies in Modem Natural Science. Sonderheft von Social Studies of Science, 11 (1): 3-10
Dembowski, H/Krause, M., 1987: Laborstudie Atomphysik. Unveröffentlichter Forschungsbericht. Universităt Bielefeld Fakultät fir Sociologie

Foucault, M., 1979: Überwachen und Strafen. Frankfiut' M.: Suhrkamp

Galison, P., 1987: How Experiments End Chicago Univ. of Chicago Press.

Garfinkel, H./Lynch, M./Livingston, E., 1981: The Wark of a Discovery Science Construed with Materials from the Optically Discovered Pulsar. Philosophy of Social Science 11:131-158

Geertz, C, 1973: The Interpretation of Cultures New York: Basic Books

Grice, P., 1975: Logic and Conversation. In: P. Cde und J. Morgan (Hrsg.): Syntax and Semantics 3, Speech Acts. New York: Academic Press

Hirschauer, S., 1987: Laborstudie Sexualwissenschaft Projektbericht. Universität Bielefeld UniversitätкSchwerpunkt Wissenschaftsforschung

Knorr, K., 1977: Producing and Reproducing Knowledge: Descriptive ar Constructive? Social Science Information 16:669-696

Knort Cetina, K., 1981; 1984: The Manufacture of Knowledge. An Essay on the Constructivist and Contextual Nature of Science Oxford Pergamon Press Deutsche Übersetzung: Die Fabrikation von Frkenntnis. Zur Anthropologie der Naturwissenschaft. Frankfurt/M.: Suhrkamp

Knorr Cetina, K./Amann, K., 1988: Image Dissection in Natural Scientific Inpuiry. Sondertheft von Social Sukc dies of Science (eingereicht)

Knorr Cetina, K.Mulkay, M., 1983: Science Observed Perspectives in the Social Study of Science. London und Beverly Hills: Sage

Krück, C, 1988: Laborstudie Laser- und Oberflächenphysik. Projektbericht. Universität Bielefeld, Fakultät fir Soziologie

Kutschmann, W., 1986: Der Naturwissenschaffler und sein Körper. Frankfurt/M.: Suhrkamp

Latour, B., 1987: Science in Action: How to Follow Scientists and Engineers Through Society, Cambridge Harvard University Press

Latour, B./Wodgar, S., 1979: Laboratory Life. The So dal Construction of Scientific Facts. Beverty Hïls Sage

Lynch, M., 1985: Art und Artifact in Laboratory Science A Study of Shop Work and Shop Talk in a Research Laboratory. London: Routledge and Kegan Paul

MacKenzie, D., 1981: Statistics in Britain, 1865-1930: The Social Construction of Soientific Knowledge Edinburgh: Edinburgh University Press

Mannheim, K., 1954: Ideology and Utopia: An Introduction to the Sociology of Knowledge. New York: Harcourt Brace and World

Mulkay, M./Gilbert, G. N., 1984: Opening Pandora's Box: A Sociological Analysis of Scientist's Discourse Cambridge: Cambridge University Press

Schmidt, K. H., 1988: Texte und Bilder in kamplexen Wissensprozessen. Unveröffentlichte Dissertation Universität Bielefeld, Fakultät firr Soziologie 
Schütze, F., 1976: Zur Hervorlockung und Analyse von Erzahlungen thematisch relevanter Geschichten im Rahmen soziologischer Feldforschung, in: Arbeitsgruppe Bielefelder Soziologen (Hrsg.): Kommunikative Sozialforschung. München: $159-260$

Smith, R. W.Tatarewicz, J. N., 1985: Replacing aTechnology: The Large Space Telescope and CCDs. Proceedings of the IEEE 73 (7): 1221-1235
Traweek, S., 1988: Buying Time and Talking Space: The Culture of the Particle Physics Community. Boston: Harvard University Press

Watchirs, G./Schuster, J., 1987: The Eighteenth Century Problem: Natural PhiJosophy, Experiment, and Discourse in Post-Kuhnian Perspective. Papier präsentiert am 12th Annual Meeting der Society for Sociai Studies of Science, Worcester, Mass., November 1987 